\title{
Avaliação da aprendizagem de ética em curso de formação de professores de Ensino Fundamental
}

\section{Maria Judith Sucupira da Costa Lins}

Doutora em Educação, UFRJ

Professora Adjunta da

Faculdade de Educação, UFRJ

mariasucupiralins@terra.com.br

Paulo Ruas Santos

Mestre em Educação, UFRJ

Pesquisador do GPEE/UFRJ

Professor Adjunto da FE/UFRJ

João Eduardo Bastos

Malheiro de Oliveira

Doutorando em Educação, UFRJ

Pesquisador do GPEE/UFRJ

joao.malheiro@bol.com.br

\section{Monique Marques Longo}

Mestrando em Educação, UFRJ

Pesquisadora do GPEE/UFRJ

moniqueml@ig.com.br

\section{Edson Seiti Miyata}

Mestrando em Educação, UFRJ

Pesquisador do GPEE/UFRJ

esmivata@yahoo.com.br

Juliana Viana Mählmann Muniz Dantas Pós-graduação em Psicologia, UFJF

Pesquisadora do GPEE/UFRJ jvmmd@ibest.com.br

\section{Resumo}

Professores não se sentem sempre confiantes em relação aos tópicos de Educação Moral que ensinam às crianças no Ensino Fundamental. Por este motivo decidimos conhecer como e o que os futuros professores nos cursos de Ensino Médio de formação de professores no Brasil aprendem sobre Educação Moral. De acordo com a lei educacional brasileira (9394/96) a Educação Moral deve ser ensinada como Tema Transversal. Não há uma disciplina especial para este assunto na escola. Educação Moral é chamada Ética e deve ser aprendida por meio de todas as disciplinas escolares. Esta pesquisa teve como objetivo descobrir como é ensinado e como estes estudantes entendem Educação Moral. $\bigcirc$ estudo de Alasdair Maclntyre sobre Virtude foi a base teórica. Foi pedido aos estudantes que falassem sobre o significado das virtudes e respondessem questões escritas e orais. Pediu-se que dessem conceitos de Família, Escola e País e que descrevessem a si próprios em diferentes situações. A metodologia da "Escuta Sensível" de René Barbier foi escolhida e os dados foram estudados de acordo com a análise 
de Laurence Bardin. Resultados mostram que os estudantes estão interessados na formação em Educação Moral, embora haja diferentes problemas concernentes à aprendizagem de ética.

Palavras-chave: Educação moral/ética. Temas transversais. Formação de professores.

\section{Abstract}

Assessing how future teachers learn ethics in

\section{training courses}

Teachers don't feel always confident concerning Moral Education topics they teach to children in elementary school. Because of this we decided to know how and what future teachers in Brazilian education courses learn about Moral Education. According to the Brazilian educational law (9394/96) Moral Education must be taught as a Transverse Theme. There is not a special subject for this topic in school. Moral Education is called Ethics and must be learnt through all the school subjects. This research aimed to discover how it is taught and how these students understand Moral Education. Alasdair Maclntyre's study about Virtue was the theoretical basis. Students were asked to talk about meaning of virtues and answered written and oral questions. They were asked to give concepts to Family, School and Country and to describe themselves in different situations. Rene Barbier's "sensible listening" methodology was chosen and data were studied according to Laurence Bardin's analyze. Results show that students are interested in Moral Education studies, though there are different problems concerning ethics learning.

Keywords: Moral Education/ Ethics. Transverse Theme. Teacher's training course.

\section{Resumen \\ Evaluación del aprendizaje de ética en curso de formación de profesores de los primeros ensino fundamental ${ }^{1}$}

Los maestros no siempre se sienten confiados en relación a los tópicos de Educación Moral que enseñan a los niños en el Ensino Fundamental. Por estos motivos, decidimos conocer como y lo qué los futuros profesores, hoy en los cursos de Ensino Médio ${ }^{2}$ de formación de profesores en el Brasil, aprenden sobre Educación Moral. Según la ley educacional brasileña (n 9394/96), la Educación Moral debe ser enseñada como un tema transversal, o sea, no hay una disciplina especial para este sujeto en la escuela. Educación Moral es llamada de Ética y debe ser aprendida por medio de todas las disciplinas escolares. Esta investigación tiene por escopo descubrir como se enseña y como estos estudiantes estudian la Educación Moral. La base teorica fue el estudio de Alasdair Maclntyre sobre la virtud. Se pidió a los estudiantes que hablaran sobre el significado de las virtudes y contestaran a cuestiones escritas y orales. Se les pidió que elaboraran conceptos de Familia, Escuela y

\footnotetext{
${ }^{1}$ Ensino Fundamental es como se llama en Brasil el conjunto de los 8 primeros años letivos, de los 7-8 a los 14-15 años de edad. ${ }^{2}$ Ensino Médio es como se llama en Brasil el conjunto de los 3 últimos años pre-universitarios, de los 15-16 a los 17-18 años de edad
} 
Pais, y que se describieran a si mismos en diversas situaciones. Fue elegida la metodología de la "escucha sensible" de René Barbier, y los dados fueran estudiados de acuerdo al analisis de Laurence Bardin. Los resultados muestran que los estudiantes están interesados en la formación en Educación Moral, aunque hayan todavía diversos problemas acerca del aprendizaje de la ética.

Palabras clave: Educación moral/ética. Temas transversales. Formación de profesores.

\section{Introdução}

Esta pesquisa trata de um problema educacional freqüentemente observado nas escolas. É sabido que os professores encontram dificuldades no que se refere ao ensino da Educação Moral para alunos de todos os níveis escolares. Não é fácil estabelecer conceitos de moral nem trabalhar a compreensão destes, por isso se observa a necessidade de uma prática pedagógica adequada. Diante deste problema real no campo da Educação, a pesquisa procurou investigar a questão a fim de que pudesse sugerir caminhos que de alguma maneira ajudem a resolvê-lo.

A Prática de Educação Moral é indicada como ética devido à nova denominação utilizada pela Lei de Diretrizes e Bases - LDB, Lei no 9394 (BRASIL, 1996). Além disso, a determinação legal, explicitada pelos Parâmetros Curriculares Nacionais (2000) - PCN, indica que o ensino de Ética seja realizado por meio de Temas Transversais.

A partir de observações da atuação de alguns professores do Ensino Fundamental e dos problemas práticos que enfrentam no ensino-aprendizagem de Moral/Ética, foi considerado que seria necessária uma pesquisa que se voltasse para a etapa anterior, isto é, quando estes professores são ainda alunos de Ensino Médio, preparando-se para o exercício de Magistério no Ensino Fundamental.

Como hipótese, consideramos que as dificuldades enfrentadas por professores em exercício - eles não conseguem ensinar Ética por meio de situações de sala de aula podem ser provenientes da ausência de uma formação adequada em seus cursos de preparação concernente à Educação Moral/Ética. Por isso, nas entrevistas, uma das perguntas foi justamente questionar como os alunos viam algumas atitudes positivas ou negativas dos professores observadas na sala de aula. Veremos em seguida as respostas.

Uma vez que não existe uma formação completa sem a contribuição ou ausência da formação da família e da comunidade, questões concernentes a estes aspectos foram consideradas relevantes na nossa pesquisa em relação aos alunos. Interessamonos em examinar outros aspectos que influenciam habitualmente essa formação ética integral como bairro onde moram, seus interesses, grau de instrução da família, religião e qual a motivação que tinham para serem professores.

\section{Referencial teórico}

A fundamentação teórica desta pesquisa está na filosofia de Alasdair Maclntyre (1984, 1990, 1991, 1998, 1999). Suas idéias são um verdadeiro desafio para filósofos e educadores e estão expressas em extensa bibliografia. Destacamos como base para esta pesquisa a sua obra es- 
sencial, After Virtue, inicialmente publicada em 1981, e revista em 1984, cuja tradução para o português apareceu em 2001. Completamos nosso referencial com outra obra sua, ainda não traduzida para o português, intitulada: Dependent Rational Animals: Why Human Beings Need the Virtues (MACINTYRE, 1999).

Leituras regulares foram realizadas por todos os pesquisadores e foram feitas discussões para melhor compreensão desta difícil literatura, uma vez por semana. De acordo com a teoria de Maclntyre (1984), é importante aprender e praticar as virtudes, principalmente a justiça, para se tornar uma pessoa moral. Virtude é apresentada por este autor como a possibilidade de viver uma vida Moral em oposição ao Emotivismo, o qual está amplamente difundido na sociedade atual. Para melhor compreensão, embora de forma sintética, lembremos como Maclntyre (2001, p. 300, grifo do autor) conceitua essa teoria:

Emotivismo é a doutrina para a qual todos os julgamentos avaliativos e mais especificamente todos os julgamentos morais não passam de expressões de preferência, expressões de atitude ou sentimento, na medida em que são morais ou avaliativos em caráter.

A partir do Emotivismo, Maclntyre afirma que estamos numa situação peculiar, em que se perdeu a racionalidade e se passou para uma ética vivida por meio da tomada de decisões segundo preferências e opiniões pessoais. Essa teoria se caracteriza pela preocupação com a posição individual para definição de problemas e questões filosóficas, sempre a partir de elementos prazerosos.
Além deste autor, cuja teoria consistiu o fundamento básico, as contribuições de Piaget (1973) e de Kohlberg (1981) sobre o desenvolvimento moral da criança também foram consideradas.

\section{Objetivo}

Conforme projeto inicial da Pesquisa, os objetivos eram dois:

- Discutir as questões teóricas fundamentais da Ética e a conseqüente prática da Educação Moral no Ensino Fundamental.

- Identificar, analisar as práticas pedagógicas de Educação Moral/Ética visando possibilitar aos alunos do Curso de Formação de Professores de Ensino Fundamental a construção de programas Educação Moral/Ética.

Evidentemente, nossa expectativa é que os resultados obtidos sejam também utilizados para outras pesquisas afins, não só para que os atuais alunos e professores melhorem o ensino/aprendizagem de ética/moral, mas para todos os futuros professores.

\section{Metodologia}

Foi escolhida a metodologia da "Escuta Sensível", criada por René Barbier (1997). Esta forma de Pesquisa Ação apresenta muitas vantagens sobre outras para o estudo de um tema como o da presente pesquisa. Por meio da "Escuta Sensível" foi possível compreender mais profundamente tantos os alunos como seus professores, além de que oferece oportunidade de melhor se aprender sobre como os futuros professores estão progredindo nos estudos de Ética. 
Os futuros professores foram observados durante as aulas e também em situações extraclasse. Acompanhamos suas atividades, interesses, preferências e rejeições, sempre em conversas com eles. Também o comportamento geral foi observado, em relação aos colegas, professores e o pessoal administrativo da escola.

Foram solicitados a falar sobre o significado de Virtude e também responderam a questionários que lhes foram apresentados como entrevistas semi-estruturadas. Conceitos de Família, País e Escola também foram pedidos, de modo que eles puderam expressar sua compreensão destes fundamentos da vida social e moral. Conversações livres com estes estudantes aconteceram continuamente, oferecendo ricos subsídios para as conclusões da pesquisa. Também a Diretora, a Assessora da Direção, o Coordenador e os Professores foram entrevistados.

Os dados obtidos foram analisados segundo a proposta de Bardin (1996), e, depois da categorização, fizemos as inferências que nos permitiram chegar aos resultados, que serão descritos no item desenvolvimento e comentados nas conclusões.

A pesquisa foi iniciada em março de 2005 e acompanhou uma turma de 21 alunos da primeira série do Ensino Médio de formação de professores de uma escola estadual do Rio de Janeiro e 11 professores. Em 2006 continuamos com o contato com esses alunos, já na $2^{\circ}$ série - além de alguns novos que ingressaram nessa turma - e os mesmos professores, durante o primeiro semestre. Durante o segundo semestre, fizemos a análise dos dados que vinham sendo coletados desde o princípio dos encontros um ano antes e elaboramos as conclusões que se seguem.

\section{Desenvolvimento}

À medida que os estudantes tomavam contato com o vocabulário específico da Ética, tanto por meio dos professores, que ocasionalmente incluíram este Tema Transversal em suas atividades, como em nossas conversas, seu interesse pelo assunto aumentou.

Os estudantes fizeram alguns trabalhos sobre Ética a pedido de seus professores, tais como painéis e cartazes e nós aproveitamos este material como centro de discussão. Os estudantes começaram a correlacionar elementos conceituais com o próprio comportamento e também com as possibilidades de ensino de Ética às crianças que no futuro serão os seus alunos na primeira etapa do Ensino Fundamental. Exemplos concretos e situações da vida real foram utilizados para discussão e análise de modo que os estudantes estivessem todo o tempo conferindo as questões propostas com a situação em que vivem.

\section{Dados da pesquisa com os professores}

Apresentamos abaixo os dados obtidos por meio das entrevistas com os professores. e suas respectivas análises. A entrevista consistia de 5 perguntas que objetivam detectar como os professores estavam formados nos conceitos de ética e moral, como viam e entendiam a proposta da LDB (BRASIL, 1996), de trabalhar a ética como tema transversal e quais estratégias adotavam para viver essa exigência legal. 
As perguntas e suas categorizações foram as seguintes:

1 - Como você pode conceituar os termos Ética e Moral?

\begin{tabular}{|l|c|l|l|l|l|l|}
\hline O que ética? & \multicolumn{3}{|l|}{ O que é moral? } & Relação entre ética e moral \\
\hline Respeito & $\mathbf{4}$ & Não existe & 1 & Complementação entre agir e valores & 1 \\
\hline valores & $\mathbf{7}$ & Em branco & $\mathbf{3}$ & Alicerces da civilização & 1 \\
\hline Certo e errado & $\mathbf{4}$ & costumes & $\mathbf{3}$ & Em branco & $\mathbf{9}$ \\
\hline Quero para viver & 1 & valores & $\mathbf{4}$ & & \\
\hline reflexão & 2 & Leis & 1 & & \\
\hline & & ideologia & 1 & & \\
\hline & & preconceitos & 1 & & \\
\hline
\end{tabular}

Conforme podemos observar acima, os professores manifestaram o domínio de um vocabulário específico da área ética/moral, embora isto não garanta que haja uma prática no seu quotidiano. Muitas vezes o discurso pode não ser o que o eles pensam ou vivem, mas um reflexo de uma linguagem que está sendo usada na sociedade. Apesar de uma grande incidência de respostas sobre a relação entre ética e valores (7/ 11) ou sobre a relação entre moral e valores $(4 / 11)$, chamou a atenção que a maioria $(9 / 11)$ teve dificuldade em relacionar ética e moral.

\section{2 - Ética/Moral se ensina e se aprende na escola?}

\begin{tabular}{|l|c|}
\hline Sim & $\mathbf{8}$ \\
\hline Não & 0 \\
\hline Sim e Não & 1 \\
\hline Talvez & 1 \\
\hline Em branco & 1 \\
\hline
\end{tabular}

Em relação ao segundo quadro sobre se ética/moral se ensina e se aprende na escola, ficou evidenciado que $\operatorname{sim}(8 / 11)$. Supostamen- te todos os professores deveriam responder afirmativamente, o que não aconteceu.

\section{3 - Como você entende a proposta da} LDB 9394/96 de Temas Transversais?

\begin{tabular}{|l|l|}
\hline Às vezes é possível & 1 \\
\hline $\begin{array}{l}\text { Depende da formação } \\
\text { dos Professores }\end{array}$ & 1 \\
\hline Importantes para a reflexão & 1 \\
\hline $\begin{array}{l}\text { Difícil pela falta } \\
\text { de conteúdo }\end{array}$ & 1 \\
\hline Para aprender & 1 \\
\hline Depende da motivação & 1 \\
\hline Fantástico & $\mathbf{2}$ \\
\hline Interdisciplinariedade & $\mathbf{3}$ \\
\hline Substituição da família e lgreja & 1 \\
\hline
\end{tabular}

Com relação ao entendimento do que consiste os Temas Transversais, a dispersão presente nas respostas pode nos levar a interpretar como a ausência do entendimento da proposta. No entanto, há um pequeno bloco $(3 / 11)$ que identificou como interdisciplinaridade, o que se aproxima do verdadeiro conceito dos temas transversais. 
4 - E quanto à aprendizagem da Ética entendida como tema transversal?

\begin{tabular}{|l|l|}
\hline Necessidade de conteúdos & 1 \\
\hline Depende exemplo do professor & 3 \\
\hline Depende da cultura & $\mathbf{4}$ \\
\hline Tem muito Valor & $\mathbf{5}$ \\
\hline
\end{tabular}

Sobre a aprendizagem da Ética entendida como tema transversal, quase metade $(5 / 11)$ considera que esta "tem muito valor". Chamou-nos a atenção que $7 / 11$ das respostas relativizaram a aprendizagem da ética como tema transversal, condicionando esta ao "exemplo do professor" (3/1 1) ou à cultura (4/1 1).

5 - $O$ que você tem feito, ou planeja fazer, em relação ao ensino/aprendizagem da Ética/Moral com os alunos da turma de $1 \frac{\mathrm{a}}{2 \mathrm{a}}$ (dependendo do ano) série do curso Médio de Formação de Professores de 2005/2006 (dependendo do ano)?

\begin{tabular}{|l|c|}
\hline Conteúdo & $\mathbf{7}$ \\
\hline $\begin{array}{l}\text { Aproveitamento de } \\
\text { oportunidades }\end{array}$ & $\mathbf{2}$ \\
\hline Conscientizar & 1 \\
\hline Exemplo & 1 \\
\hline
\end{tabular}

Continuando, observamos o planejamento do ensino/aprendizagem da ética/moral na sala de aula e foi notado que a maioria $(9 / 11)$ tenciona relacioná-lo com o conteúdo (7/11) ou com o aproveitamento de oportunidades $(2 / 11)$.

\section{Dados da pesquisa com os alunos}

No que se refere às entrevistas dos alunos, conforme já foi abordado aci$\mathrm{ma}$, as perguntas procuravam detectar como as possíveis influências da família, da comunidade onde vivem, das ambições, metas e interesses de vida pessoal e profissional influenciam na formação ética e moral.

Diferentemente dos professores, apresentamos abaixo as perguntas e suas categorizações e em seguida a análise do grupo, pois várias perguntas e respostas se entrelaçaram na nossa análise. Identificamos os alunos pela letra $A x$, para manter o necessário sigilo, mas ao mesmo tempo oferecer possibilidades de novas análises.

\section{Questionários dos alunos}

\section{Ano do Nascimento}

\begin{tabular}{|l|l|}
\hline 1988 & $\mathrm{~A} 1, \mathrm{~A} 12=2$ \\
\hline 1989 & $\mathrm{~A} 2, \mathrm{~A} 3, \mathrm{~A} 5, \mathrm{~A} 7, \mathrm{~A} 8, \mathrm{~A} 10, \mathrm{~A} 11, \mathrm{~A} 15, \mathrm{~A} 16, \mathrm{~A} 17, \mathrm{~A} 18, \mathrm{~A} 19, \mathrm{~A} 20=13$ (17 anos) \\
\hline 1990 & $\mathrm{~A} 4, \mathrm{~A} 6, \mathrm{~A} 9, \mathrm{~A} 13, \mathrm{~A} 14, \mathrm{~A} 21=6$ \\
\hline
\end{tabular}




\section{Bairro onde mora}

\begin{tabular}{|l|l|}
\hline Jacarepaguá & $\mathrm{A} 1, \mathrm{~A} 8, \mathrm{~A} 13, \mathrm{~A} 14, \mathrm{~A} 21=5$ \\
\hline Vargem Grande & $\mathrm{A} 2, \mathrm{~A} 10, \mathrm{~A} 12=3$ \\
\hline Lins de Vasconcelos & $\mathrm{A} 3, \mathrm{~A} 11=3$ \\
\hline Taquara & $\mathrm{A} 4$ \\
\hline Vargem Pequena & $\mathrm{A} 5, \mathrm{~A} 9 . \mathrm{A} 16=3$ \\
\hline Anil & $\mathrm{A} 6$ \\
\hline Engenho da Rainha & $\mathrm{A} 7$ \\
\hline Recreio & $\mathrm{A} 15$ \\
\hline Duque de Caxias & $\mathrm{A} 17$ \\
\hline Méier & $\mathrm{A} 18$ \\
\hline Barra da Tijuca & $\mathrm{A} 19$ \\
\hline Rocha Miranda & $\mathrm{A} 20$ \\
\hline
\end{tabular}

\section{Com quem mora}

\begin{tabular}{|l|l|}
\hline Pai, mãe e irmão & $\mathrm{A} 1, \mathrm{~A} 2, \mathrm{~A} 7, \mathrm{~A} 14=4$ \\
\hline Pai e mãe & $\mathrm{A} 3, \mathrm{~A} 4, \mathrm{~A} 5, \mathrm{~A} 9, \mathrm{~A} 10, \mathrm{~A} 11, \mathrm{~A} 12, \mathrm{~A} 18, \mathrm{~A} 19=9$ \\
\hline Mãe & $\mathrm{A} 8, \mathrm{~A} 16, \mathrm{~A} 20, \mathrm{~A} 21=4$ \\
\hline Mãe e padrasto & $\mathrm{A} 13$ \\
\hline Pai & $\mathrm{A} 15$ \\
\hline Avó & $\mathrm{A} 17$ \\
\hline
\end{tabular}

\section{Profissão do pai}

\begin{tabular}{|l|l|}
\hline colocador & $\mathrm{A} 1$ \\
\hline pedreiro & $\mathrm{A} 2, \mathrm{~A} 12$ \\
\hline Professor & $\mathrm{A} 3$ \\
\hline aposentado & $\mathrm{A} 4, \mathrm{~A} 15$ \\
\hline Motorista & $\mathrm{A} 5$ \\
\hline Taxista & $\mathrm{A} 7$ \\
\hline Jardineiro & $\mathrm{A} 8$ \\
\hline Mestre de obra & $\mathrm{A} 9$ \\
\hline Recepcionista & $\mathrm{A} 10$ \\
\hline Engenheiro & $\mathrm{A} 13$ \\
\hline Padeiro & $\mathrm{A} 14$ \\
\hline Segurança & $\mathrm{A} 16,21$ \\
\hline Auxiliar de pintor & $\mathrm{A} 17$ \\
\hline Servente & $\mathrm{A} 18$ \\
\hline Não tem & $\mathrm{A} 6, \mathrm{~A} 11, \mathrm{~A} 19, \mathrm{~A} 20$ \\
\hline
\end{tabular}




\section{Escolaridade do pai}

\begin{tabular}{|l|l|}
\hline $2^{\circ}$ grau completo & $\mathrm{A} 1, \mathrm{~A} 4, \mathrm{~A} 7, \mathrm{~A} 10, \mathrm{~A} 13, \mathrm{~A} 12, \mathrm{~A} 19=7$ \\
\hline $7^{\mathrm{a}}$ série & $\mathrm{A} 2, \mathrm{~A} 8, \mathrm{~A} 17=3$ \\
\hline Ensino Superior & $\mathrm{A} 3$ \\
\hline $1^{\circ}$ grau completo & $\mathrm{A} 5, \mathrm{~A} 11, \mathrm{~A} 14, \mathrm{~A} 18=4$ \\
\hline Superior incompleto & $\mathrm{A} 15$ \\
\hline Analfabeto & $\mathrm{A} 21$ \\
\hline Não tem & $\mathrm{A} 6, \mathrm{~A} 9, \mathrm{~A} 12, \mathrm{~A} 20=4$ \\
\hline
\end{tabular}

\section{Profissão da mãe}

\begin{tabular}{|l|l|}
\hline Professora & $\mathrm{A} 1, \mathrm{~A} 3$ \\
\hline Doméstica & $\mathrm{A} 2, \mathrm{~A} 5, \mathrm{~A} 6, \mathrm{~A} 10, \mathrm{~A} 12=5$ \\
\hline Enfermeira- auxiliar & $\mathrm{A} 4$ \\
\hline Dona de casa & $\mathrm{A} 7, \mathrm{~A} 9, \mathrm{~A} 11, \mathrm{~A} 17, \mathrm{~A} 20, \mathrm{~A} 21=6$ \\
\hline Caixa & $\mathrm{A} 8, \mathrm{~A} 18$ \\
\hline Garçonete & $\mathrm{A} 13$ \\
\hline Enfermeira- superior & $\mathrm{A} 14$ \\
\hline Artesã & $\mathrm{A} 16$ \\
\hline Vendedora & $\mathrm{A} 19$ \\
\hline Não tem & $\mathrm{A} 15$ \\
\hline
\end{tabular}

\section{Escolaridade da mãe}

\begin{tabular}{|l|l|}
\hline $2^{\circ}$ grau completo & $\mathrm{A} 1, \mathrm{~A} 4, \mathrm{~A} 6, \mathrm{~A} 7 . \mathrm{A} 19=5$ \\
\hline $1^{\circ}$ grau completo & $\mathrm{A} 2, \mathrm{~A} 5, \mathrm{~A} 10, \mathrm{~A} 18, \mathrm{~A} 20=5$ \\
\hline Ensino superior & $\mathrm{A} 3, \mathrm{~A} 14$ \\
\hline $1^{\circ}$ grau incompleto & $\mathrm{A} 8, \mathrm{~A} 16, \mathrm{~A} 17, \mathrm{~A} 21=4$ \\
\hline $2^{\circ}$ grau incompleto & $\mathrm{A} 9, \mathrm{~A} 12,13, \mathrm{~A} 15=4$ \\
\hline Não tem & $\mathrm{A} 11$ \\
\hline
\end{tabular}




\section{8. "Hobby"}

\begin{tabular}{|l|l|}
\hline Igreja & $\mathrm{A} 1$ \\
\hline Praia & $\mathrm{A} 1$ \\
\hline Desenho & $\mathrm{A} 2, \mathrm{~A} 20$ \\
\hline Poesia & $\mathrm{A} 2$ \\
\hline Escrever & $\mathrm{A} 3, \mathrm{~A} 7, \mathrm{~A} 13$ \\
\hline Ouvir musica & $\mathrm{A} 3, \mathrm{~A} 4, \mathrm{~A} 10, \mathrm{~A} 12, \mathrm{~A} 14, \mathrm{~A} 17, \mathrm{~A} 19=7$ \\
\hline Diversão em geral & $\mathrm{A} 4$ \\
\hline Ler & $\mathrm{A} 5, \mathrm{~A} 14, \mathrm{~A} 15, \mathrm{~A} 18, \mathrm{~A} 21=5$ \\
\hline Jogar bola & $\mathrm{A} 6, \mathrm{~A} 15$ \\
\hline Internet & $\mathrm{A} 6, \mathrm{~A} 9, \mathrm{~A} 13$ \\
\hline Sair com amigos & $\mathrm{A} 6, \mathrm{~A} 9, \mathrm{~A} 10, \mathrm{~A} 11, \mathrm{~A} 12=5$ \\
\hline Remar & $\mathrm{A} 7$ \\
\hline Dançar & $\mathrm{A} 8, \mathrm{a} 10, \mathrm{~A} 11, \mathrm{~A} 13=4$ \\
\hline Shopping & $\mathrm{A} 11$ \\
\hline Trabalhar com crianças na igreja & $\mathrm{A} 14$ \\
\hline Cinema & $\mathrm{A} 16$ \\
\hline Ver Tv & $\mathrm{A} 18$ \\
\hline
\end{tabular}

\section{Religião}

\begin{tabular}{|l|l|}
\hline Assembléia de Deus & $\mathrm{A} 1, \mathrm{~A} 3, \mathrm{~A} 14, \mathrm{~A} 17=4$ \\
\hline Evangélica & $\mathrm{A} 2, \mathrm{~A} 15, \mathrm{~A} 16=3$ \\
\hline Sem religião & $\mathrm{A} 4, \mathrm{~A} 12, \mathrm{~A} 13, \mathrm{~A} 19=4$ \\
\hline Católica & $\mathrm{A} 4, \mathrm{~A} 6, \mathrm{~A} 7, \mathrm{~A} 8, \mathrm{~A} 9, \mathrm{~A} 10, \mathrm{~A} 11, \mathrm{~A} 18, \mathrm{~A} 21=9$ \\
\hline Espírita & $\mathrm{A} 20$ \\
\hline
\end{tabular}

\subsection{Freqüenta?}

\begin{tabular}{|l|l|}
\hline SIM & $\mathrm{A} 1, \mathrm{~A} 2, \mathrm{~A} 3, \mathrm{~A} 4, \mathrm{~A} 5, \mathrm{~A} 6, \mathrm{~A} 8, \mathrm{~A} 10, \mathrm{~A} 11, \mathrm{~A} 12, \mathrm{~A} 13, \mathrm{~A} 14, \mathrm{~A} 15, \mathrm{~A} 16, \mathrm{~A} 17, \mathrm{~A} 18, \mathrm{~A} 19, \mathrm{~A} 21$ \\
\hline $\mathrm{NA} O$ & $\mathrm{~A} 7, \mathrm{~A} 9, \mathrm{~A} 20$ \\
\hline
\end{tabular}




\section{Por que está na escola?}

\begin{tabular}{|c|c|}
\hline Porque quer ser professor & $\begin{array}{l}\mathrm{A} 1, \mathrm{~A} 2, \mathrm{~A} 3, \mathrm{~A} 8 . \mathrm{A} 10, \mathrm{~A} 11, \mathrm{~A} 12, \mathrm{~A} 13, \\
\mathrm{~A} 16, \mathrm{~A} 17, \mathrm{~A} 18, \mathrm{~A} 19, \mathrm{~A} 20, \mathrm{~A} 21=14\end{array}$ \\
\hline Novidade & A4 \\
\hline Por gostar & A5 \\
\hline Por gostar de criança & A6 \\
\hline Para ter profissão & A7 \\
\hline Pra pagar faculdade & A7 \\
\hline Por acaso & A9 \\
\hline Oferecer opções ao futuro & A15 \\
\hline
\end{tabular}

\section{O que espera da escola?}

\begin{tabular}{|l|l|}
\hline Formação & $\mathrm{A} 1, \mathrm{~A} 2, \mathrm{~A} 3, \mathrm{~A} 11=4$ \\
\hline Empregabilidade & $\mathrm{A} 1, \mathrm{~A} 8, \mathrm{~A} 9, \mathrm{~A} 13, \mathrm{~A} 15, \mathrm{~A} 17, \mathrm{~A} 18, \mathrm{~A} 21=8$ \\
\hline Ensino & $\mathrm{A} 4, \mathrm{~A} 7, \mathrm{~A} 9, \mathrm{~A} 19=4$ \\
\hline Qualificação & $\mathrm{A} 5, \mathrm{~A} 12=2$ \\
\hline Base para o futuro & $\mathrm{A} 6$ \\
\hline Amizade & $\mathrm{A} 7$ \\
\hline Preparo para ensinar & $\mathrm{A} 10$ \\
\hline Não espera muito & $\mathrm{A} 14, \mathrm{~A} 20=2$ \\
\hline Sem resposta & $\mathrm{A} 16$ \\
\hline
\end{tabular}

\section{O que vai fazer depois do término do curso?}

\begin{tabular}{|l|l|}
\hline Ser bom profissional & $\mathrm{A} 1$ \\
\hline Faculdade de Pedagogia & $\mathrm{A} 2, \mathrm{~A} 8, \mathrm{~A} 17, \mathrm{~A} 18=4$ \\
\hline Faculdade de Fonaoudiologia & $\mathrm{A} 2=1$ \\
\hline Faculdade & $\mathrm{A} 3, \mathrm{~A} 5, \mathrm{~A} 11, \mathrm{~A} 12, \mathrm{~A} 19=5$ \\
\hline Continuar estudando & $\mathrm{A} 4=1$ \\
\hline Não sei & $\mathrm{A} 6, \mathrm{~A} 9=2$ \\
\hline Faculdade de historia & $\mathrm{A} 7=1$ \\
\hline Fac. De Letras & $\mathrm{A} 10=1$ \\
\hline Fac. De educação física & $\mathrm{A} 10=1$ \\
\hline Dar aula & $\mathrm{A} 13, \mathrm{~A} 21=2$ \\
\hline Engenharia & $\mathrm{A} 13$ \\
\hline Psicopedagogia & $\mathrm{A} 14$ \\
\hline Direito & $\mathrm{A} 15$ \\
\hline Psicologia & $\mathrm{A} 16$ \\
\hline Artes & $\mathrm{A} 20$ \\
\hline
\end{tabular}




\section{Por que deseja ser professor?}

\begin{tabular}{|l|l|}
\hline Sonho ser professora de biologia & $\mathrm{A} 1$ \\
\hline Gosto de crianças & $\mathrm{A} 2, \mathrm{~A} 3, \mathrm{~A} 6, \mathrm{~A} 10, \mathrm{~A} 12, \mathrm{~A} 18, \mathrm{~A} 21=7+\mathrm{A} 14$ \\
\hline Papel no futuro & $\mathrm{A} 3$ \\
\hline Auto- conhecimento & $\mathrm{A} 4$ \\
\hline Gostar de ensinar & $\mathrm{A} 5, \mathrm{~A} 8, \mathrm{~A} 15, \mathrm{~A} 21=4$ \\
\hline Sonho de minha mãe & $\mathrm{A} 6$ \\
\hline Não sei & $\mathrm{A} 7, \mathrm{~A} 9$ \\
\hline Ajudar/fazer o bem & $\mathrm{A} 7, \mathrm{~A} 14=2$ \\
\hline Identifica com pedagogia & $\mathrm{A} 17$ \\
\hline Identificação com a profissão & $\mathrm{A} 11$ \\
\hline Olhar por alguém & $\mathrm{A} 13$ \\
\hline Vocação & $\mathrm{A} 14$ \\
\hline Gosta de psicologia & $\mathrm{A} 16$ \\
\hline Todos na família são professores & $\mathrm{A} 19$ \\
\hline Desenvolver a arte-terapia & $\mathrm{A} 20$ \\
\hline
\end{tabular}

\section{Conceito de Escola}

Obs: Dois alunos levaram para o plano pessoal

Conceito geral:

\begin{tabular}{|l|l|}
\hline Base/preparação para o futuro & $\mathrm{A} 3, \mathrm{~A} 20, \mathrm{~A} 19, \mathrm{~A} 18, \mathrm{~A} 17, \mathrm{~A} 16, \mathrm{~A} 15, \mathrm{~A} 14, \mathrm{~A} 11, \mathrm{~A} 7=$ \\
\hline Função de ensinar & $\mathrm{A} 4$ \\
\hline Iniciação a uma vida de saber & $\mathrm{A} 5$ \\
\hline Sem o colégio não somos ninguém \\
\hline Preparação para o futuro & $\mathrm{A} 7$ \\
\hline Ensinar & $\mathrm{A} 9$ \\
\hline Educar & $\mathrm{A} 9$ \\
\hline Fazer amizade & $\mathrm{A} 9$ \\
\hline Aprender & $\mathrm{A} 9, \mathrm{~A} 10, \mathrm{~A} 12, \mathrm{~A} 15, \mathrm{~A} 21, \mathrm{~A} 5=6$ \\
\hline Segunda casa & $\mathrm{A} 13$ \\
\hline Socialização & $\mathrm{A} 15, \mathrm{~A} 17$ \\
\hline Lugar para ser alguém na vida & $\mathrm{A} 16$ \\
\hline Conseguir objetivos & $\mathrm{A} 16$ \\
\hline
\end{tabular}


Conceito restrito à escola que freqüentam:

\begin{tabular}{|l|l|}
\hline Não tão boa & A1 \\
\hline Dá para estudar & A1 \\
\hline Ensino & A2 \\
\hline Estrutura ruim & A2 \\
\hline Não se preocupa com os alunos & A8 \\
\hline Professor não se preocupa com a aprendizagem & A8 \\
\hline
\end{tabular}

\section{Conceito de família}

Conceito geral:

\begin{tabular}{|l|l|}
\hline Razão de viver & A1 \\
\hline União necessária para estrutura emocional & A3 \\
\hline Só pai, mãe e irmão & A4 \\
\hline Não servem para muita coisa & A4 \\
\hline Apoio & $\mathrm{A} 5, \mathrm{~A} 15, \mathrm{~A} 16, \mathrm{~A} 19$ \\
\hline Companheirismo & $\mathrm{A} 5, \mathrm{~A} 15$ \\
\hline Ajuda & $\mathrm{A} 6 \mathrm{~A} 13$ \\
\hline Base/tudo & $\mathrm{A} 7, \mathrm{~A} 9, \mathrm{~A} 10, \mathrm{~A} 12, \mathrm{~A} 14$, \\
& $\mathrm{A} 16, \mathrm{~A} 17, \mathrm{~A} 18, \mathrm{~A} 20, \mathrm{~A} 21$ \\
\hline Segurança & $\mathrm{A} 11$ \\
\hline Importante para a formação & $\mathrm{A} 14$ \\
\hline Convivência & $\mathrm{A} 17$ \\
\hline Estimulo & $\mathrm{A} 19$ \\
\hline Força para lutar & $\mathrm{A} 20$ \\
\hline
\end{tabular}

Conceito especifico:

\begin{tabular}{|l|l|}
\hline Cada um ama do seu jeito & A2 \\
\hline "Somos bem unidos" & A8 \\
\hline
\end{tabular}




\section{Conceito de país}

\begin{tabular}{|l|l|}
\hline Deve mudar & $\mathrm{A} 1$ \\
\hline Ser melhor & $\mathrm{A} 1$ \\
\hline Desastre & $\mathrm{A} 2$ \\
\hline Casa & $\mathrm{A} 3$ \\
\hline Pátria & $\mathrm{A} 3, \mathrm{~A} 15$ \\
\hline Nação & $\mathrm{A} 3$ \\
\hline Abandonado & $\mathrm{A} 4$ \\
\hline Sem utilidade & $\mathrm{A} 4$ \\
\hline Lar & $\mathrm{A} 5$ \\
\hline Beleza natural & $\mathrm{A} 6$ \\
\hline Tristeza com política & $\mathrm{A} 6$ \\
\hline O que somos & $\mathrm{A} 7$ \\
\hline O que defendemos & $\mathrm{A} 7$ \\
\hline O que queremos & $\mathrm{A} 7$ \\
\hline Confundiu com família & $\mathrm{A} 8, \mathrm{~A} 10$ \\
\hline Sem resposta & $\mathrm{A} 9$ \\
\hline Legal & $\mathrm{A} 12$ \\
\hline Não pensa sobre porque não leva a nada & $\mathrm{A} 13$ \\
\hline Instituição onde vivo e tenho que respeitar as leis, mesmo não aceitando & $\mathrm{A} 14$ \\
\hline Terra amada & $\mathrm{A} 15$ \\
\hline Um lixo & $\mathrm{A} 16$ \\
\hline Política rígida & $\mathrm{A} 16$ \\
\hline Riquezas naturais & $\mathrm{A} 17$ \\
\hline Costumes & $\mathrm{A} 17$ \\
\hline Diversidade de povos & $\mathrm{A} 18$ \\
\hline Diversas culturas, crenças e classes sociais & $\mathrm{A} 19$ \\
\hline Lugar que forma cidadãos direitos & $\mathrm{A} 20$ \\
\hline & \\
\hline & \\
\hline
\end{tabular}




\section{Os Professores abrem espaço para questões além dos conteúdos? Quando?} SIM

\begin{tabular}{|l|l|}
\hline Prof $^{a} X$ falou de greve & $\mathrm{A} 2, \mathrm{~A} 14, \mathrm{~A} 17, \mathrm{~A} 20, \mathrm{~A} 21$ \\
\hline Confiança, apoio e incentivo & $\mathrm{A} 3$ \\
\hline Um assunto puxa outro & $\mathrm{A} 4$ \\
\hline Situações do cotidiano e país & $\mathrm{A} 5$ \\
\hline Eles próprios & $\mathrm{A} 7$ \\
\hline Atualidade & $\mathrm{A} 7$ \\
\hline Sobre tudo & $\mathrm{A} 9$ \\
\hline Discussão de opiniões diferentes & $\mathrm{A} 10$ \\
\hline Nulo & $\mathrm{A} 12, \mathrm{~A} 13, \mathrm{~A} 16$ \\
\hline Política e violência & $\mathrm{A} 19, \mathrm{~A} 15$ \\
\hline A Reforma & $\mathrm{A} 17$ \\
\hline Novelas & $\mathrm{A} 19$ \\
\hline Favelas & $\mathrm{A} 20$ \\
\hline Guerra & $\mathrm{A} 21$ \\
\hline
\end{tabular}

NÃO

\begin{tabular}{|l|l|}
\hline So a matéria deles & $\mathrm{A} 1, \mathrm{~A} 8, \mathrm{~A} 6$ \\
\hline Não se importam & $\mathrm{A} 11$ \\
\hline Sem exemplos & $\mathrm{A} 3, \mathrm{~A} 8$ \\
\hline \hline
\end{tabular}




\section{Quais as questões que gostam de discutir em aula? Por quê?}

\begin{tabular}{|l|l|}
\hline Trabalhos de grupo & $\mathrm{A} 1$ \\
\hline Futuro & $\mathrm{A} 2$ \\
\hline Lidar com crianças, arte de ensinar & $\mathrm{A} 3$ \\
\hline Questões culturais & $\mathrm{A} 4$ \\
\hline Sem resposta & $\mathrm{A} 5$ \\
\hline Não gosta de discutir & $\mathrm{A} 6$ \\
\hline Tudo & $\mathrm{A} 7, \mathrm{~A} 9$ \\
\hline Só aula & $\mathrm{A} 8, \mathrm{~A} 12$ \\
\hline Falar mal e bem dos professores & $\mathrm{A} 9$ \\
\hline "meninos, lógico!" & $\mathrm{A} 9$ \\
\hline "fofocadinha básica" & $\mathrm{A} 9$ \\
\hline Sobre trabalhos a fazer & $\mathrm{A} 10$ \\
\hline Juventude & $\mathrm{A} 11$ \\
\hline Prof: conteúdos, colegas: deveres e zoeira & $\mathrm{A} 13$ \\
\hline Formação normalista & $\mathrm{A} 14$ \\
\hline Nada especial & $\mathrm{A} 15$ \\
\hline Referente a melhorar a escola & $\mathrm{A} 16$ \\
\hline Política e economia & $\mathrm{A} 17$ \\
\hline Sexualidade & $\mathrm{A} 19$ \\
\hline Identidade & $\mathrm{A} 19$ \\
\hline Artes & $\mathrm{A} 20$ \\
\hline Política do Brasil & $\mathrm{A} 21$ \\
\hline Segurança e impunidade & $\mathrm{A} 21$ \\
\hline
\end{tabular}

\section{Quando tem briga na escola, de que maneira o professor intervém?}

\begin{tabular}{|l|l|}
\hline Não presenciei & $\mathrm{A} 1, \mathrm{~A} 3, \mathrm{~A} 4, \mathrm{~A} 8, \mathrm{~A} 9, \mathrm{~A} 14, \mathrm{~A} 15, \mathrm{~A} 19, \mathrm{~A} 21$ \\
\hline Convida-os a diretoria & $\mathrm{A} 2, \mathrm{~A} 12$ \\
\hline Buscando motivos & $\mathrm{A} 5, \mathrm{~A} 7$ \\
\hline Não tomam atitude & $\mathrm{A} 6, \mathrm{~A} 11$ \\
\hline Sugere solução & $\mathrm{A} 7$ \\
\hline Procura acabar com a briga & $\mathrm{A} 10, \mathrm{~A} 12$ \\
\hline Sendo justos, da maneira correta & $\mathrm{A} 13$ \\
\hline Sem resposta & $\mathrm{A} 16, \mathrm{~A} 17, \mathrm{~A} 18, \mathrm{~A} 20$ \\
\hline
\end{tabular}


20. Você se recorda de alguma situação em que o professor tenha sido um exemplo para você, ou suas palavras tenham influenciado na sua decisão?

\begin{tabular}{|l|l|}
\hline Sim & Não \\
\hline A1, A14, A16 & A5 \\
\hline $\begin{array}{l}\text { A2, A12 dizem coisas que nos animam } \\
\text { quando temos problemas }\end{array}$ & A6 \\
\hline A3 percebo o prazer de estarem aqui & $\mathrm{A} 10$ \\
\hline $\begin{array}{l}\text { A4 o exemplo construiu a } \\
\text { personalidade que ela é hoje }\end{array}$ & $\mathrm{A} 13$ \\
\hline A7, A11 influência na escolha profissional & $\mathrm{A} 15$ uma professora não é bom exemplo \\
\hline $\begin{array}{l}\text { A8 a assiduidade da professora } \\
\text { apesar de ter problemas. }\end{array}$ & $\mathrm{A} 18$, não explica direito \\
\hline A9 mas não me lembro & Professor W- 2 vezes \\
\hline A15 a maioria dá bom exemplo & A20 \\
\hline Professora Y - 5 vezes & \\
\hline A18 porque exige & \\
\hline A19 não entrou em greve & \\
\hline $\begin{array}{l}\text { A20 entrou em greve } \\
\text { (ensinou a lutar pelos direitos) }\end{array}$ & \\
\hline A21 a professora Z me abriu os olhos & \\
\hline \hline
\end{tabular}

\section{Quando você tem uma decisão a tomar, a quem você pede orientação?}

\begin{tabular}{|l|l|}
\hline $\mathrm{A} 1, \mathrm{A6}$ & Ninguém \\
\hline $\mathrm{A} 2$ & Irmãs \\
\hline $\mathrm{A} 3, \mathrm{~A} 8, \mathrm{~A} 9, \mathrm{~A} 11, \mathrm{~A} 14, \mathrm{~A} 16, \mathrm{A18}, \mathrm{A19}, \mathrm{A} 20, \mathrm{~A} 21$ & Mãe \\
\hline $\mathrm{A} 3, \mathrm{~A} 4, \mathrm{~A} 15$ & Deus \\
\hline $\mathrm{A} 3, \mathrm{~A} 9, \mathrm{~A} 13, \mathrm{~A} 18, \mathrm{~A} 19, \mathrm{~A} 21$ & Amigos \\
\hline $\mathrm{A} 4, \mathrm{~A} 18$ & Consciência \\
\hline $\mathrm{A} 4$ & Sentimentos \\
\hline $\mathrm{A} 5, \mathrm{~A} 7, \mathrm{~A} 10, \mathrm{~A} 12$ & Pais \\
\hline $\mathrm{A} 15$ & Pai \\
\hline A16 & Avô \\
\hline A17 & Conselheira da Igreja \\
\hline
\end{tabular}




\section{Comentários sobre os dados}

A pesquisa foi realizada numa turma com 21 alunos, inicialmente da $1^{a}$ série e em seguida, em 2006, na $2^{a}$ série do Ensino Médio da Formação de Professores de Ensino Fundamental. Notamos que a grande maioria $(80 \%)$ está na faixa etária prevista, para esse nível de escolarização. Foi observado também que a maioria mora muito longe da escola. Um aluno mora em outro município (Duque de Caxias). É possível que isto se deva ao fato de haver pouca opção de escolas normais na cidade. A maioria dos alunos (61\%) mora com a família em seu conceito básico. Além desses, 1 dos alunos mora com uma família constituída de uma mãe e um padrasto. 6 alunos moram apenas com um adulto: pai, mãe e avó.

Um grupo de pais (33\%) concluiu o segundo grau - hoje chamado de Ensino Médio, pela LDB 9394/96 (BRASIL, 1996) -, e trabalham em profissões de pouca qualificação. Apenas um terminou o Curso Superior, exercendo a profissão de professor. Outro tem o Curso Superior incompleto e hoje está aposentado, numa profissão que não nos foi dita. De um outro grupo de 33\%, 19\% concluiu o primeiro grau e $14 \%$ cursou até a $7^{a}$. série. 4 alunos não informaram a escolaridade do pai e um disse que era analfabeto.

As mães, de um grupo de 43\%, 23\% concluíram o $2^{\circ}$ grau e $19 \%$ não concluíram. $\bigcirc$ mesmo acontece com um outro grupo de igual quantidade com relação ao primeiro grau. Duas têm Curso Superior, exercendo profissões compatíveis com essa qualificação: uma é professora e outra é enfermeira. Não foi especificado o grau de escolaridade de uma das mães.
Pesquisamos os interesses de lazer dos alunos e nisto perguntamos o que tinham como hobby. Assistir TV, para nossa surpresa, só foi citada apenas uma vez, o que pode indicar que isto já está incorporada à sua vida quotidiana. A maioria (33\%) mostrou preferência por ouvir música, seguindo-se dois grupos de $24 \%$ que preferem ler - apesar de que não indicaram que tipo de leitura, o que pode invalidar um pouco este item - e sair com os amigos. Aproxima-se desses, dançar que equivale a $19 \%$. Depois, apareceram internet e escrever, com 14\%. O restante dos interesses ficou bastante disperso.

Quanto ao aspecto da religião, $86 \%$ afirmaram que freqüentam um culto. Observamos que não existe uma grande variedade de religiões. $43 \%$ são católicos, 19\% são da Assembléia de Deus (estão separados dos Evangélicos porque assim definiram os alunos) e 14\% são Evangélicos (o que não indica propriamente um grupo, pois existem várias denominações sob esta rubrica). 19\% disseram não ter religião, apesar de que disseram que freqüentam o culto.

Perguntamos aos alunos porque estão na escola. $66 \%$ afirmaram que sua motivação era ser professor. Na pergunta seguinte, na qual indagamos o que espera da escola, 8 alunos (38\%) especificaram que queriam formação e ensino, o que comprova a resposta anterior. Outros 38\% esperam apenas empregabilidade e a pergunta seguinte mostra que, de fato, estão na escola apenas para conseguir recursos financeiros visando pagar uma faculdade (81\%). Destes, apenas $41 \%$ tencionam ingressar no Curso Superior na área de Educação e afins. Isto nos pareceu uma estratégia muito interessante, tendo em vista que muitos alunos têm dificuldade para almejar metas mais elevadas. 
Quando perguntamos sobre porque queria ser professor $62 \%$ deu uma resposta coerente com a profissão. "Gosto de crianças. Me sinto bem ao lado delas. Elas precisam de mim e eu delas", disse uma aluna. $\bigcirc$ restante deu justificativas dispersas. "Porque é o sonho da minha mãe", disse uma outra.

Nesta pesquisa, buscamos no referencial teórico, a filosofia de Maclntyre (1984, 1990, 1991, 1998, 1999), conceitos básicos que nos auxiliaram na compreensão dos nossos alunos e na realidade que os cerca. Estes conceitos - Escola, Família e País - se referem à idéia de tradição enquanto fundamento da humanidade, ponto de destaque para a Ética segundo Maclntyre. Com relação ao primeiro, Escola, 28\% dos alunos não abstraíram o conceito e responderam se restringindo apenas à escola que freqüentam. Isto pode indicar que esses alunos estão ainda numa fase operacional concreta segundo a perspectiva piagetiana. As respostas se referiam às deficiências do ensino, à estrutura da escola, ao ambiente agradável, entre outras. Com relação aos que abstraíram, destacamos que a grande maioria (50\%) a relaciona com a preocupação futura, $30 \%$ com o aprender e o restante com a socialização.

Na questão sobre o conceito de Família, $66 \%$ dos alunos a ressaltam como a base da organização da vida deles. Os demais salientaram o aspecto sentimental destas. Dois alunos a referenciaram como algo dispensável: "Sinceramente não serve para muita coi$\mathrm{sa}^{\prime}$, afirmou um aluno. Por fim, evidenciando o conceito de País, 29\% se aproximou da idéia formal. $32 \%$ se prenderam a enumerar atributos, alguns destacando as belezas naturais e outros seus aspectos negativos. Um aluno chegou a afirmar do seu próprio país que o considerava um lixo.
Entrando mais profundamente no objetivo da pesquisa, perguntamos aos alunos se os professores abriam espaço para falar sobre outros assuntos além dos conteúdos da disciplina. 33\% disse que não, o que não quer dizer que estes professores sejam desinteressados, mas talvez porque sintam falta de tempo e/ou estejam comprometidos no seguimento do programa obrigatório. Os demais, responderam que sim, dizendo que os professores abriam espaço para temas de política (maioria), cultura e experiências de vida. Os assuntos preferidos que mais se destacaram para discussão em sala de aula foram sobre os próprios professores, conteúdos escolares, sexualidade, profissão, lazer e cidadania. Esta variação temática que ocorre numa mesma proporção pode mostrar uma grande diversidade de observação dos alunos.

Continuando neste enfoque da pergunta anterior, vimos o que acontece em sala de aula em relação à discussão de outros assuntos. Passamos a analisar o que os alunos gostariam que fosse trazido para o debate em aula. Além dos temas "juventude e trivialidades", percebemos que os demais coincidiam com o que os professores apresentam.

Com relação à reação dos professores diante de brigas na escola, chamou-nos a atenção que quase metade dos alunos (43\%) afirmou nunca ter presenciado tal acontecimento, o que não é coerente com a nossa observação. Note-se que 4 alunos não responderam, o que corrobora a nossa suspeita. As demais respostas, com exceção de tentativa de solução (19\%), se distribuíram eqüitativamente nos seguintes itens: convite a ir à diretoria, busca do motivo da briga e ausência de atitude. 
Indagando-se sobre se o exemplo do professor influenciava os alunos, notamos que as respostas se dividem entre sim e não. As respostas positivas mostram que esses professores estão exercendo influência na "escolha profissional", na "solução de problemas pessoais" e na "formação da personalidade". Destacou-se neste grupo um único professor com $24 \%$ das respostas dos alunos. Nas respostas negativas, $43 \%$ não se recordam de que os professores tenham sido um exemplo para eles.

Por fim, foi questionado a quem o aluno se dirige quando precisa de uma orientação na tomada de decisão. De forma bastante visível, a mãe (50\%) ocupa um papel preponderante na escolha dos alunos como a pessoa que vai orientá-los. Acrescente-se a estas 4 respostas referindo-se aos pais (pai e mães).Em segundo lugar, estão os amigos, com $28 \%$ das respostas dadas pelos alunos. Observe-se ainda que 4 alunos citaram Deus como seu orientador.

\section{Conclusões}

Os resultados da categorização feita a partir da análise dos dados obtidos nesta pesquisa qualitativa apontam uma falta de informação sobre Educação Moral/Ética de maneira geral. Notou-se o desconhecimento de conceitos básicos desta área do saber. Ao mesmo tempo, foi constatado que estes estudantes demonstraram um grande interesse sobre o tema da pesquisa.

Suas respostas às questões sobre Virtude, Ética e Moral mostraram que eles não haviam até então compreendido este importante domínio do conhecimento.
Entrevistas e conversas, realizadas individualmente ou em pequenos grupos mostraram uma evolução de entendimento e de comportamento nestes alunos. Demonstraram não só interesse como um avanço na compreensão de conceitos e do papel da Educação Moral/Ética na vida de todas as pessoas. Principalmente entenderam a responsabilidade referente à exigência de um aprofundamento neste tema em função de seus futuros alunos.

No que diz respeito aos professores, as observações revelam que eles têm uma grande dificuldade para lidar com o tema, tanto conceitualmente como do ponto de vista didático. Parece-nos que eles precisam ter um preparo um pouco mais adequado no que se refere à introdução de Temas Transversais simultaneamente aos conteúdos de suas disciplinas, inclusive quanto à Ética, apesar da instituição destes pelos PCN desde 1997.

Tendo em vista os nossos objetivos iniciais, consideramos que os resultados já obtidos nos permitem afirmar que foram alcançados. Além do grupo de pesquisa ter aprofundado no tema da ética, notou-se que a proposta da LDB n 9.394 (BRASIL, 1996), ainda está longe de ser efetivada. Uma possível proposta é examinar a possibilidade do retorno de uma disciplina específica na grade das escolas de preparação para os futuros professores, sobre o tema de ética e moral. Além disto a Ética deve continuar a ser trabalhada dentro do conteúdo das demais disciplinas. Um problema que despertou no grupo certa preocupação foi a imaturidade dos alunos para apreenderem conceitos éticos. Este problema motivou o grupo a realizar nova pesquisa, com o mesmo grupo de alunos na qual serão investigadas mais especificamente as possíveis causas deste problema. 


\section{Referências}

ALVES-MAZZOTTI, A. J.; GEWANDSZNAJDER, F. O método nas ciências naturais e sociais: pesquisa quantitativa e qualitativa. São Paulo: Pioneira, 1998.

BARDIN, L. L'analyse de contenu. 8e éd. corrigée. Paris: PUF, 1996.

L'approche transversale: I'écoute sensible en sciences humaines. Paris:

Anthropos, 1997.

. La recherche-action. Paris: Anthropos, 1996. (Coll. Ethno-sociologie-poche). . La recherche-action dans l'instituition éducative. Paris: Gauthier-Villars, 1977.

BUSQUETS, M. D. et al. Temas transversais em educação: bases para uma formação integral. São Paulo: Ática, 1997.

KOHLBERG, L. Essays on moral development. San Francisco: Harper \& Row Publisher, 1981.

LINS, M. J. S. C. Educação moral na encruzilhada. Educação e Contemporaneidade: revista da FAAEBA, Salvador, v. 8, n. 12, jul./dez. 2000.

- Filosofia e a prática da educação moral na perspectiva de Alasdair Maclntyre. [S.I.]: Ed. Part., 2002.

Formação do educador e a questão da Ética. Educação e Contemporaneidade: revista da FAAEBA, Salvador, v. 12, n.20, jul./dez. 2003.

. Temas transversais e aprendizagem de ética. Revista UNIVILLE, Joinville, v. 9, n. 2, p. 16-25, dez. 2004.

MACINTYRE, A. After virtue: a study in moral theory. $2^{\text {nd }}$ ed. Notre Dame, Indiana: University of Notre Dame Press, 1984.

. Dependent rational animals: why human beings need the virtues. La Salle, Illinois: Open Court Ed., 1999. (The Paul Carus lectures: 20).

. Justiça de quem ? Qual racionalidade?. Trad. Marcelo Pimenta. São Paulo: Ed. Loyola, 1991. Press, 1998.

A short history of ethics. $2^{\text {nd }}$ ed. Notre Dame, Indiana: University of Notre Dame 
Three rival versions of moral inquiry: encyclopaedia, genealogy and tradition: being Gifford lectures delivered in the University of Edinburgh in 1988. Notre Dame, Indiana: University of Notre Dame Press, 1990.

PARÂMETROS Curriculares Nacionais: apresentação dos temas transversais: ética. 2. ed. Brasília, DF, 2000. v. 8.

PIAGET, J. Le jugement moral chez l'enfant. Paris: PUF, 1973.

Recebido em: 12/01/2007

Aceito para publicação em: 07/05/2007 